\title{
A DINÂMICA, OS PRINCIPAIS PROBLEMAS E AS QUALIDADES NO DESENVOLVIMENTO DE UM CURSO DE LICENCIATURA EM EDUCAÇÃO FÍSICA NA MODALIDADE A DISTÂNCIA
}

\author{
Ari Lazzarotti Filho \\ Universidade Federal de Goiás, Goiânia, Goiás, Brasil \\ Fernanda Cruvinel \\ Instituto Federal de Goiás, Goiânia, Goiás, Brasil \\ Ana Márcia Silva \\ Universidade Federal de Goiás, Goiânia, Goiás, Brasil \\ Margarete Zambeli da Silva \\ Secretaria Municipal de Educação, Goiânia, Goiás, Brasil \\ Guenther Carlos Feitosa de Almeida \\ Instituto Federal de Goiás, Inhumas, Goiás, Brasil
}

\begin{abstract}
Resumo
A pesquisa buscou compreender como um Curso de Licenciatura em Educação Física na modalidade a distância vem sendo desenvolvido. A metodologia foi o estudo de caso através da análise do PPC e de 16 entrevistas semiestruturadas. O curso em questão apresentou uma estrutura em fase de consolidação com experiências didático-pedagógicas em nível inicial e em fase de experimentação. Destacam-se como problemas a falta de estrutura dos Polos, o não domínio das tecnologias e informação e comunicação - TIC e a intensificação do trabalho docente. Como principais qualidades extrai-se a autonomia, o letramento digital, a flexibilidade de horário, a democratização do acesso ao ensino superior e a melhoria da comunicação.
\end{abstract}

Palavras-chaves: Formação de professores; Educação a distância; Educação Física.

\section{INTRODUÇÃO E PROBLEMATIZAÇÃO}

Observa-se no Brasil da última década, uma expansão exponencial de novos cursos de graduação em Educação Física-EF (SILVA et al. 2009); acompanhando este aumento, vem ocorrendo a criação e ampliação de cursos na modalidade à distância, fato significativo, visto que, em tese, contraria a tradição desse campo, marcadamente identificado pelo saber fazer, pelas vivências e pela experimentação corporal. Tal formação feita por meio dessa modalidade não é comum e inexiste nas principais universidades que trabalham com a EaD no mundo.

A abertura dos cursos de EF na modalidade à distância trouxe desconfianças em sua 
DOI 10.5216/rpp.v18i3.34504

capacidade de formação profissional num campo carregado de especificidades 
(LAZZAROTTI FILHO, 2011) e pelo seu ineditismo, torna-se relevante um estudo mais abrangente, a fim de apresentar de forma descritiva a dinâmica do curso, bem como seus principais problemas e qualidades.

Estudos sobre a formação em EF na modalidade presencial são bastante comuns (FIGUEIREDO (2004), PIRES E NEVES (2002), GONZÁLEZ (2004), NASCIMENTO (2004) e REZER (2010), dentre outros), mas estudos que relacionam a EF com a modalidade à distância praticamente inexistem, por isso a importância da apresentação, mesmo que panorâmica, de algumas características para a compreensão de aspectos que a fundamentam.

$\mathrm{Na}$ literatura acadêmica em língua portuguesa, muitos termos têm sido empregados para denominar a modalidade que dispensa a presença física num mesmo espaço e tempo entre os envolvidos no processo educacional. Assim, Educação à Distância (EaD), aprendizagem aberta, aprendizagem flexível, formação à distância, formação on-line, educação em rede, ensino à distância, educação aberta são expressões que emergem para expressar essa modalidade de educação. Este rol terminológico é identificado também em outras nacionalidades e para Lito (2008) a utilização destas expressões são invenções pontuais sem respaldo ou comprovação de consenso de uso, o que dificulta o intercâmbio de ideias, experiências e avanços na utilização de uma terminologia.

Segundo Pereira (2009) e Belloni (2003), o seu conceito tem sido apresentado mais no confronto e na diferenciação com a educação presencial do que na afirmação do que venha a ser a EaD. Apresentaremos algumas de suas características, as quais podem nos ajudar a compreendê-la, sem, contudo, entrarmos no debate conceitual, o qual ainda necessita de consensos no campo.

A EaD é uma educação centrada na mediação por tecnologias que, segundo Nipper (1989), pode ser caracterizada por três gerações. Em um primeiro momento se difundiu mediante a adoção de apostilas que chegavam até o estudante pelos Correios; posteriormente, propagou-se através das ondas do rádio e da televisão, e, num terceiro e atual momento, por utilização das tecnologias de rede. A sua expressão mais conhecida, sobretudo no Brasil, é a de educação à distância.

Pesquisadores como Taylor (1999) ampliam essa tipologia de três gerações para cinco, desdobrando a EaD de terceira geração em modelos flexíveis. Tais modelos são do tipo inteligentes como processos de desenvolvimento e avanços na própria tecnologia de terceira geração. Já Rivoltella (2008) afirma que as três gerações tinham como paradigma a perspectiva do "à distância" e com o advento da web 2.0 um novo paradigma emerge, o colaborativo.

Uma característica que foi se ampliando e se tornou central na contemporaneidade é a relação entre o tempo e o espaço, o que nos remete a pensar nas formas de sociabilidade, no aumento da velocidade e na diminuição dos espaços em função dos desenvolvimentos tecnológicos, os quais tanto nos aproximam, quanto nos distanciam. Belloni, (2003, p. 54) afirma que,

A interação entre o professor e o estudante ocorre de modo indireto no espaço (a distância, descontínua) e no tempo (comunicação diferida, não simultânea), o que acrescenta complexidade ao já bastante complexo processo de ensino e aprendizagem na EaD.

Para que ocorra o processo ensino-aprendizagem não há necessidade da presença entre os envolvidos num mesmo espaço e tempo. Assim, professores, estudantes, gestores e demais envolvidos estabelecem uma relação centrada na mediação por tecnologias para 0 
desenvolvimento da aprendizagem, o que não significa dizer que a sua presença tecnológica seja nova na educação, como nos alerta a própria Belloni (2003).

$\mathrm{O}$ processo de educação à distância pode ser mediado por ferramentas assíncronas e síncronas. Com as ferramentas assíncronas não há necessidade dos envolvidos estarem logados, conectados ao mesmo tempo como, por exemplo, ocorre quando encaminhamos uma mensagem via correio eletrônico ou fórum. Já nas ferramentas síncronas, há necessidade dos sujeitos envolvidos na comunicação estarem logados, conectados simultaneamente para possibilitar a interação.

As características da $\mathrm{EaD}$ apresentadas acima podem nos ajudar a pensar como os cursos de EF vêm desenvolvendo seus processos formativos, visto sua recente entrada nessa modalidade. Algumas questões são centrais nessa análise, tais como são estruturados esses cursos; o que os diferencia do modelo presencial; como desenvolvem suas atividades de ensino, e, por fim, como garantem o desenvolvimento dos saberes das práticas corporais. Essas e outras questões nos motivaram a desenvolver um estudo de caso para compreender como um curso de EF nessa modalidade acontece e quais os seus principais problemas e qualidades.

\section{METODOLOGIA}

A pesquisa em questão caracteriza-se como um estudo de caso de perspectiva diagnóstica descritivo-exploratória realizada por meio da análise documental e de entrevistas semiestruturadas em relação a um Curso de Licenciatura em EF na modalidade à distância. A referida investigação foi desenvolvida no período de agosto de 2010 a agosto de 2011.

O presente estudo teve como material empírico de análise: a) Entrevista semiestruturada com dezesseis agentes do curso $(n=16)$, sendo desses, cinco com professores autores/formadores $(n=5)$, Coordenadora do curso $(n=1)$; três com Orientadores Acadêmicos $(n=3)$, quatro com Tutores Presenciais $(n=4)$ e dois com estudantes $(n=2)$; e, b) O Projeto Pedagógico do Curso.

A seleção dos sujeitos para as entrevistas englobou a totalidade dos professores que trabalharam no curso no período da entrevista, além do coordenador do curso, sendo que os orientadores acadêmicos e estudantes foram escolhidos através de sorteio. A entrevista foi realizada através de um roteiro semiestruturado, gravado em áudio, transcrito e devolvido para os entrevistados. Todos assinaram o termo de consentimento livre eesclarecido.

As informações foram inseridas, categorizadas e analisadas com o apoio do Software Nvivo 9.1 através de três nós com as seguintes ocorrências: 1) A dinâmica do curso DC (76), 2) Principais problemas PP (89) e 3) As qualidades Q (37). Para identificação das codificações em cada nó, as letras expressam as iniciais do documento de origem: PPC - Projeto Pedagógico do Curso; E - entrevista, sendo PF - Professor formador; CC - Coordenador do Curso; OA - Orientador Acadêmico; TP - Tutor Presencial e E - Estudante. Os sujeitos da pesquisa foram identificados com os números de 1 a 16.

\section{ANÁLISE E DISCUSSÃO DOS DADOS}

\section{Dinâmica do curso}

O Curso de Licenciatura em EF na modalidade à distância foi aprovado no segundo edital da Universidade Aberta do Brasil (UAB) no ano de 2007 e publicado no Diário Oficial 
da união no ano de 2008. O ingresso da primeira turma ocorreu no ano de 2009 onde foram selecionados, via vestibular, 316 estudantes.

No que tange à sua concepção, o curso apresenta uma proposta de vínculo direto com o Curso de Licenciatura em EF presencial, já em funcionamento desde 1989.

O projeto político-pedagógico do curso de Licenciatura em Educação Física na modalidade de ensino à distância guarda relação direta com o curso presencial. (DCPPC).

Esta opção, segundo a coordenadora do curso, fez com que todo o corpo docente fosse o mesmo do presencial. E diferentemente daquele, foram incorporadas novas funções docentes: o Orientador Acadêmico - OA e o Tutor Presencial - TP, com a intenção de garantir a convergência entre os dois cursos, isto porque a experiência de algumas décadas de um curso poderia contribuir com o desenvolvimento do outro e, ao mesmo tempo, garantir a formação de seu quadro docente para a integração das Tecnologias de Informação e Comunicação no cotidiano da vida acadêmica.

$\mathrm{O}$ curso foi gestado e encontra-se sob a responsabilidade da unidade acadêmica sediada na cidade de Goiânia-GO onde possui uma estrutura de gestão e coordenação de todas as atividades. 


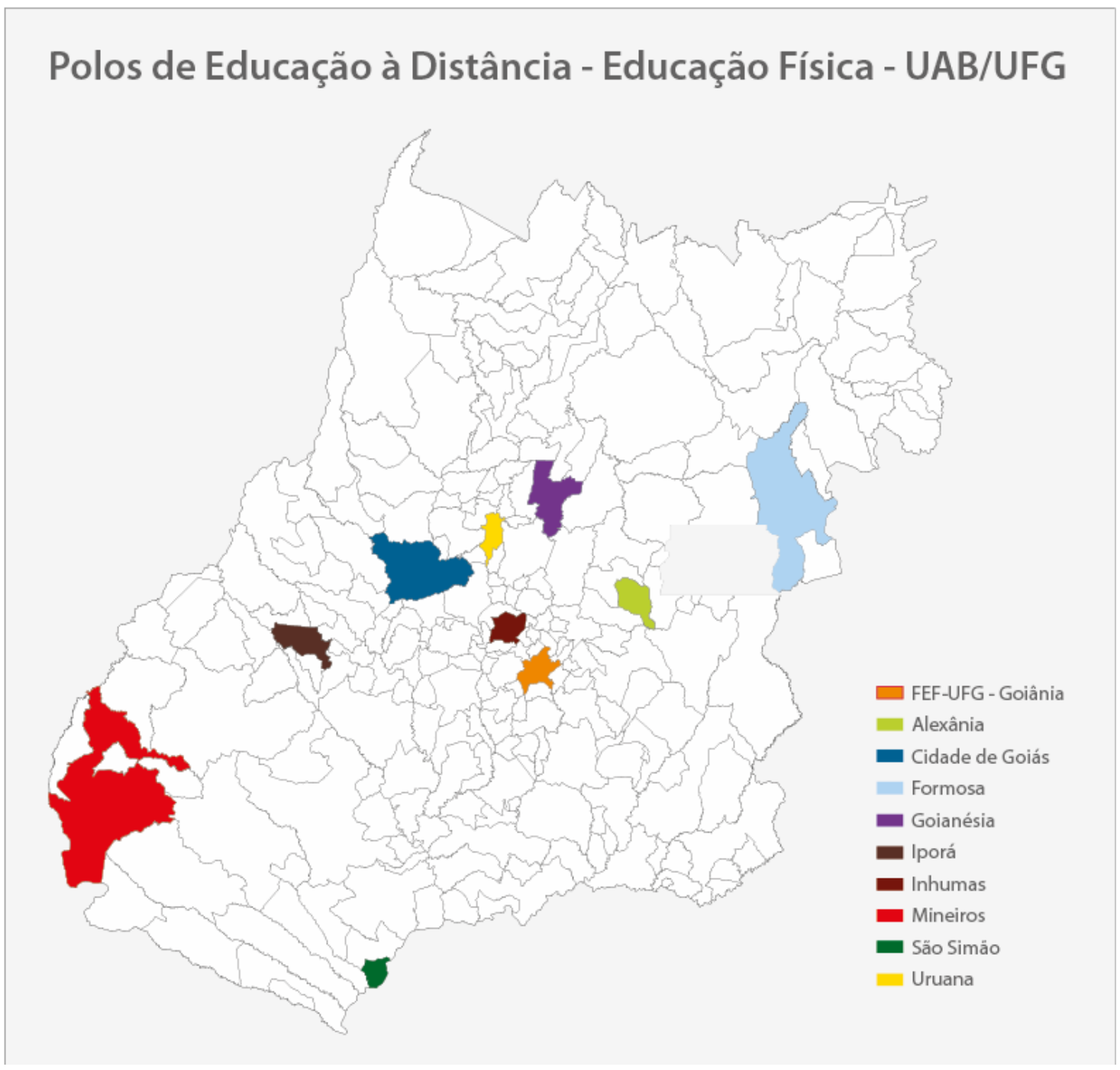

Figura I - Polos do Curso de licenciatura em Educação Física a distância Fonte: Centro Integrado de Aprendizagem em Rede - CIAR-UFG

Os estudantes estão vinculados a nove Polos (Figura I), localizados nos seguintes municípios: Alexânia, Cidade de Goiás, Formosa, Goianésia, Iporá, Inhumas, Mineiros, São Simão e Uruana, todos situados no Estado de Goiás e encontram-se distribuídos pelas várias regiões do estado com grande carência de professores de EF com formação superior.

Cada Polo possui uma estrutura com sede própria, em geral, escolas pertencentes às redes municipais ou estadual, desativadas ou compartilhadas com a educação básica. A estrutura disponível nesses Polos é constituída, em geral, por laboratórios de informática, salas de aula, além da sala da secretaria. A maioria delas ainda se encontra em estruturação, com a implantação de laboratórios e bibliotecas.

Na figura II é possível identificar a estrutura de funcionamento, desde a UAB sediada na CAPES em Brasília passando pelo Centro Integrado de Aprendizagem em Rede-CIARUFG, Coordenação do Curso FEF-UFG, até os Polos nos municípios. Para esse estudo destacam-se os aspectos relacionados à gestão, os aspectos didático-pedagógicos e a organização dos Polos. 


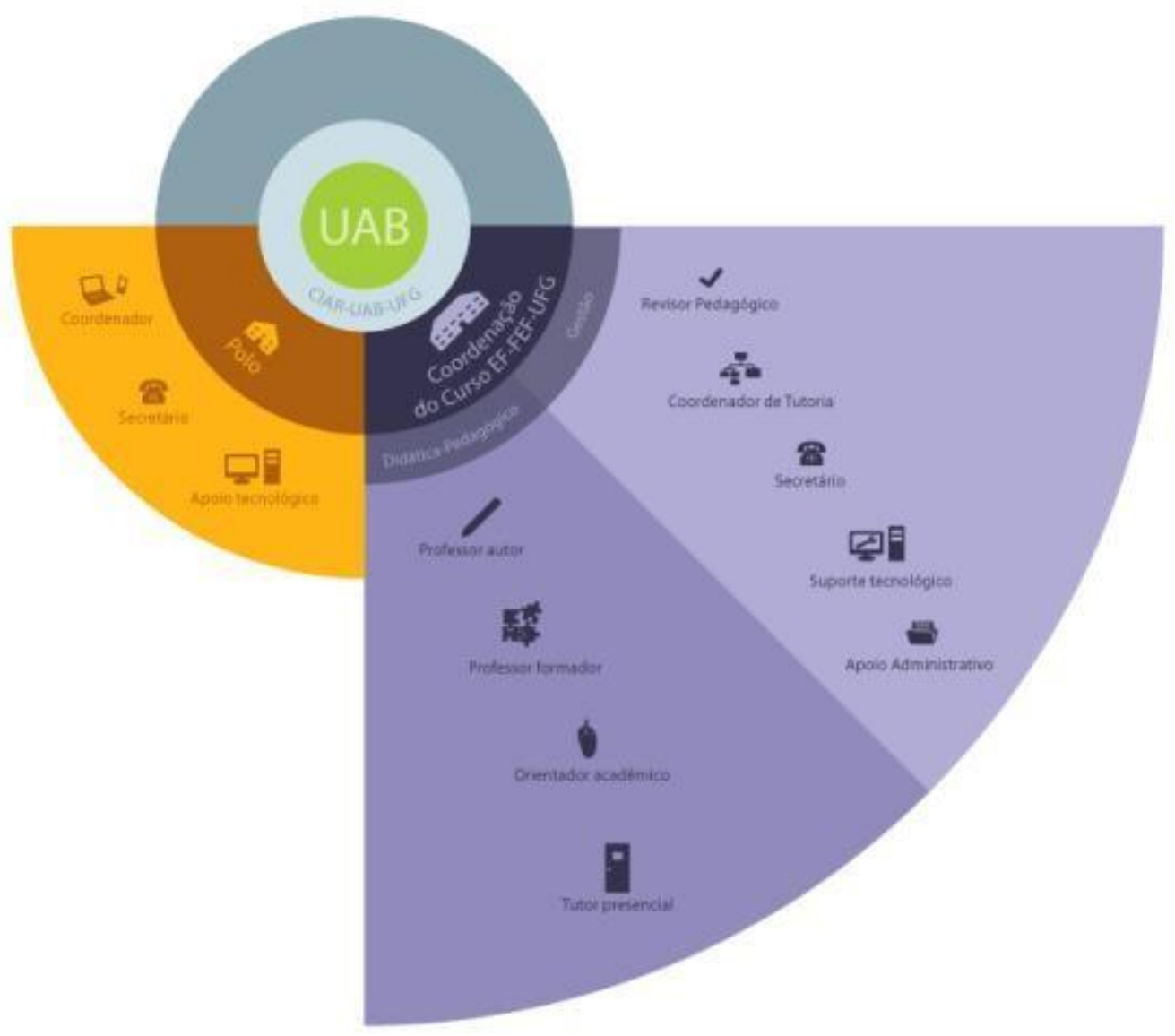

Figura II - Estrutura da Gestão e Didático-Pedagógica do curso Fonte: Centro Integrado de Educação em Rede-CIAR-UFG

No que concerne à gestão, o curso tem uma estrutura própria dentro da unidade acadêmica formada por uma equipe com Coordenador de curso, Coordenador de Tutores, Secretário, Apoio Administrativo e Suporte Tecnológico. Já o Polo é constituído por um Coordenador, um Secretário e Apoio Tecnológico.

Se no curso tradicional presencial há um professor com sua turma, no curso a distância tem uma forma própria envolvendo vários outras funções pedagógicas no processo de ensinoaprendizagem. As funções e a dinâmica de como acontece esse trabalho foi assim preconizada no PPC:

a) Professor Autor - PA - constrói o texto sobre a disciplina que será posteriormente disponibilizada na forma de material didático pedagógico no formato digital e impresso;

b) Professor Formador - PF - no caso da FEF é o próprio PA ou pelo menos um desses, visto que a autoria compartilhada do material didático tem sido uma prática comum;

c) Orientador acadêmico - OA - é um professor formado em EF com no mínimo uma especialização, vínculo como docente na rede pública ou com a Pós-Graduação. Tem a função de estabelecer a relação direta com os estudantes fazendo a mediação entre o MD, o PF e o E com o objetivo de desenvolver o processo ensino-aprendizagem; conteúdos.

d) Tutor Presencial TP - constrói a relação presencial entre o Polo, os E e os

$\mathrm{Na} \mathrm{EaD}$ o trabalho docente é ampliado e alguns estudos (BELLONI, 2003) têm apontado para o entendimento de um professor coletivo desenvolvendo suas ações a partir de 
equipes multidisciplinares e com funções diferentes do processo convencional. Assim, a dinâmica de desenvolvimento do processo de ensino-aprendizagem é realizada em blocos de duas ou três disciplinas num período de dois meses, em média oito semanas. O seu desenvolvimento é mediado num AVA, através da utilização do software MOODLE (Modular Object Oriented Distance Learning - sistema de gestão da formação e de conteúdos formativos de código aberto (open-source).

As disciplinas, em maioria, são planejadas em unidades didáticas e desenvolvidas semanalmente; a sua estrutura é composta por uma agenda, instrumento que explicita o que o estudante deve realizar; material de estudo; um fórum com uma ou mais questões para serem discutidas e é finalizada com uma atividade avaliativa. Esta última é realizada na forma de uma síntese de texto, prova online, produção textual, pesquisa online de vídeos e pesquisa de imagens relacionadas a unidade.

O fórum é a principal ferramenta utilizada para desenvolver o processo de ensino aprendizagem. É aberto pelo OA e têm tanto a finalidade de interação como de mediação pedagógica. Os fóruns de interação objetivam tirar dúvidas e criar um ambiente de trocas construído na forma de dúvidas de questões administrativas, popularizaram-se como fóruns sociais, da hora do recreio, hora do café e de notícias. Já os fóruns de mediação pedagógica ficam centrados no conteúdo específico da disciplina ou de um tema, sendo desenvolvidos geralmente com a formulação de uma questão pertinente a um texto de referência, ou por uma questão para ser discutida entre os estudantes e mediada pelo OA.

A dinâmica de trabalho do OA pode ser compreendida no depoimento abaixo:

A semana na EaD começa na segunda-feira e termina no domingo. Então o dia de domingo é o dia que eu (...) dedico mais tempo na semana para as atividades. No decorrer da semana eu procuro acompanhar mais o fórum de discussão. Proponho algumas questões para reflexão (...) e aí os alunos vão postando as respostas vão discutindo um com o outro [...] eu procuro estar fazendo essa mediação, no sentido de não deixar a discussão perder o foco, de observar se os alunos trazem algumas questões diferentes (...) um outro tempo que é no momento da correção das tarefas (...) demanda tempo, inclusive a prova é o orientador acadêmico que faz a correção (...)" (DCEOA12).

O TP desenvolve seu trabalho na mediação presencial focando sua ação no estudante e no Polo. Desse modo, por mais que algum TP procure contribuir com o desenvolvimento do conteúdo, seu papel central acaba sendo verificar a presença ou ausência dos estudantes tanto no Ambiente Virtual de Aprendizagem (AVA), quanto no Polo, além de resolver problemas técnicos que estão ao seu alcance.

O curso em questão tem tanto a especificidade da EaD como a própria especificidade do campo da EF. Essa última aparece constantemente na efetivação do curso e está associada principalmente ao saber-fazer corporal. Esse saber já foi central e determinante na formação de professores de EF como os tradicionais exames de admissão e as exigências de desempenho das habilidades técnicas nas disciplinas dos cursos de formação. Com o passar dos anos o campo vem incorporando significativamente outros aspectos, como o saber sobre o saber fazer e o saber pedagógico (LAZZAROTTI FILHO 2011). No entanto, o saber fazer corporal ainda é constituinte dessa formação, denominado, por vezes, como vivências e experiências sócio-corporais (FIQUEIREDO, 2004).

Com essa preocupação, o Curso de Licenciatura em EF na modalidade à distância incorporou na sua agenda de trabalho mais encontros presencias. Desta feita, foram previstos no PPC do curso ao menos três encontros por módulo, sendo o primeiro para fazer a 
introdução à disciplina, o segundo para atividades expositivas e o terceiro para atividades de encerramento e avaliação (DCPPC).

Com o desenvolvimento do curso, a dinâmica foi sendo alterada a fim de favorecer os encontros presenciais das disciplinas de caráter teórico-prático. A dinâmica de desenvolvimento desses encontros é planejada pelo $\mathrm{PF}$ em conjunto com os OA e desenvolvida, principalmente, por esses últimos com a colaboração do TP. Em entrevista foi possível identificar algumas formas da sua execução:

[...] por exemplo, com atletismo [...] dentro das provas de campo a gente pensava no que era básico da execução do movimento, o que é a regra básica pra ocorrência da prova de atletismo [...] pensava atividades lúdicas, algumas formas que eles também poderiam estar aplicando na escola [...] (DCEOA3).

No caso da ginástica (...) tivemos um encontro de um dia inteiro com todos os Polos onde nós organizamos espaços, partes diferentes da disciplina, para que pudessem vivenciar e compreender melhor a partir dessa vivencia que tinha sido discutida online (...) teve uma prova teórica e uma prática, e essa prática eles tiveram que dar aulas de ginástica dentro daquela perspectiva que a gente tinha trabalhado (DCEPF5).

Nunes (2008) afirma que o público alvo dessa modalidade de ensino superior tende a ser não convencional, incluindo adultos trabalhadores, pessoas que por vários motivos não podem deixar a casa, pessoas com deficiências físicas, e populações de áreas de povoamento disperso ou que, simplesmente, se encontram distantes de instituições de ensino.

Geralmente eu não tenho muito tempo lá na fazenda é meio corrido e é depois das dez horas da noite que eu começo a estudar. (DCEE6).

A partir das discussões apresentadas é possível afirmar que o curso encontra-se em fase de implantação, com dinâmicas em construção e experimentação que sua forma de trabalho se diferencia dos tradicionais cursos presenciais e que há incorporação de novas funções pedagógicas no processo de ensino e aprendizagem.

\section{Principais problemas}

$\mathrm{Na}$ análise dos problemas encontrados destacamos quatro dos mais significativos: a falta de estrutura dos Polos; o não domínio das TIC; a intensificação do Trabalho Docente; a não presença física.

$\mathrm{O}$ desenvolvimento de um curso de $\mathrm{EaD}$ demanda diversos tipos de investimentos econômicos, com parcelas significativas de recursos para o aparelhamento dos Polos, desde laboratórios didáticos até a instalação e acesso a rede mundial de computadores.

Um dos problemas é aquele que diz respeito ao acesso à rede mundial de computadores:

[...] a gente não tinha internet até mês passado [...] Pensa um curso à distância sem internet, não tem um laboratório de informática no Polo. Eu acho muito complicado né [...] (PPETP13).

A dificuldade com a internet agrava-se quando os estudantes são oriundos da zona rural e o Polo fica distante das suas casas. 
O aluno é de cidade vizinha, ele é da fazenda, ele é da zona rural, ele não é da zona urbana ali daquela cidade, então acaba que isso prejudica muito. E até mesmo a questão do aluno, do acesso dele a internet, muitas das vezes ele não tem esse acesso, ele vai lá para a zona urbana para poder conseguir ter acesso, e nem sempre ele pode ir lá todos os dias (PPEOA11).

Também se identifica como problema a falta de bibliotecas e adequação dos Polos à especificidade da EF, com espaços adequados para o desenvolvimento das práticas corporais.

Se o Polo tivesse uma estrutura preparada pra EF, os alunos iriam mais ao Polo. [...] ai então, eu estaria sendo realmente TP, ali todo dia, porque eles iriam ao Polo [...]. Eles tiveram uma aula lá de atletismo, mas se lá tivesse os materiais que hoje estão sendo usados na aula, eles iriam lá [...] (PPETP10).

A fala acima indica que os problemas estruturais, em grande medida, estão relacionados à contrapartida que cada Município ou Estado deveria proporcionar para a implantação do curso. Esse é o caso, especialmente, da ausência de acesso à internet e de espaços próprios para as práticas corporais. Tal situação é apontada como principal problema por TP e pela coordenadora do curso:

[...] eu creio que a questão seja mais estrutural e a Estado não ter dado a contrapartida [...] (PPETP13)

[...] outro grande problema é que as mantenedoras do Polo, as Prefeituras e o Estado, não estão cumprindo o termo de compromisso que assinaram e a gente até entende. Às vezes tem cidades que mudam de prefeito, para prefeito liberar depende da câmara, tem todo aquele trâmite que as vezes é complicado. [...] (PPECC).

A falta do domínio das TIC também se mostra significativa, como sendo um dos principais problemas enfrentados pelo envolvidos, seja entre os estudantes matriculados, seja por parte da equipe pedagógica e da sua integração nos processos pedagógicos. Esse domínio aparece como sendo o que se conhece como letramento ou alfabetização das mídias para os seus usos. O perfil da maioria dos estudantes indica que não são contemporâneos ao intenso desenvolvimento tecnológico que caracteriza a nova geração dos nativos digitais. Este mesmo perfil também se faz presente na equipe pedagógica a qual está ainda em fase de formação, apresentando baixa experiência com os usos e consumos das mídias.

Outro ponto que notamos ao analisarmos as entrevistas foi um traço discursivo que aponta para uma intensificação do trabalho docente na $\mathrm{EaD}$, notado tanto nas falas dos $\mathrm{PF}$, ou seja efetivos na carreira do magistério público federal, quanto dos OA, na maioria, professores das redes públicas de ensino estadual e municipal.

$\mathrm{Na}$ fala dos PF:

Quando era professora autora, eu não tinha tempo pra preparar o material, então era preparado a noite [...] (PPEPF8)

[...] Acho que é acúmulo porque o nosso autor é o professor que trabalha aqui, então ele tem uma série de outras atividades e as vezes vai deixando, vai deixando [...] (PPECC)

Tal intensificação se manifesta também no trabalho docente do OA, obviamente com nuances diferentes e com uma parcela de precarização. Isso porque eles necessitam conciliar o 
trabalho da EaD com a atividade docente cotidiana. Percebemos isso em suas falas especialmente no que diz respeito à função e remuneração de seu trabalho:

[...] pelo volume de trabalho, a bolsa com um valor muito baixo, e o fato de você dar uma disciplina e depois perder a bolsa, isso também gera certa insegurança para quem está trabalhando ali [...] (PPEOA1).

Assim e um último ponto que eu gostaria de ressaltar é a questão da remuneração que é um problema (PPEOA11).

Notamos que o trabalho com a EaD é bastante secundarizado e marginalizado nas atividade docentes, tanto do magistério superior federal, quanto do OA que não possui vínculo estável com o curso.

$\mathrm{Na} \mathrm{EaD,} \mathrm{a} \mathrm{distância} \mathrm{física} \mathrm{e} \mathrm{temporal} \mathrm{é} \mathrm{condição} \mathrm{da} \mathrm{sua} \mathrm{natureza} \mathrm{(BELONI,} \mathrm{2003),}$ mas aparece como sendo um problema para os sujeitos dessa pesquisa. Parece que a interação "face a face", tal como foi a experiência de formação e de docência da maioria dos envolvidos no curso acaba revelando a intenção e a projeção de como deveria ser a formação das futuras gerações. É possível compreender tal constatação com base em Tardif (2002) que afirma que o trabalho docente é constituído pelos saberes advindo de várias fontes e que no decorrer da vida profissional vão se incorporando no fazer pedagógico desses professores de profissão. $\mathrm{O}$ rompimento com a tradição da formação "face a face" dos agentes do curso não foi totalmente assimilado e necessita de tempo, de experiência e talvez de novas gerações para que a EaD seja amplamente incorporada ao fazer pedagógico.

\section{Qualidades do curso}

Destacam-se, neste terceiro nó de análise as qualidades do curso: o letramento digital, a flexibilidade do tempo e horário, a democratização do acesso ao ensino superior; a melhoria da comunicação através da linguagem escrita e o desenvolvimento da autonomia;

Pereira, (2009) define o termo letramento digital como o conjunto de conhecimentos que permite aos agentes envolvidos a participação nas práticas letradas mediadas por computadores no mundo contemporâneo. Ressalta que não é um conhecimento técnico para a realização de tarefas com utilização do computador e salienta que letramento digital, no sentido amplo, deve extrapolar os limites da página e construir sentidos com a interação social.

Identificamos nas entrevistas o letramento digital e a flexibilidade de tempo e do horário como valorações positivas.

A própria produção do texto, visando esse aluno à distância, então um texto que traz mais imagens a partir do uso de metáforas é [...] a própria proposição de trabalhar com novas mídias, no caso com imagens, com edição de imagens, com montagens de pequenos documentários [...] de fotografias... a ideia de tentar também de inserir o sujeito na história (QEPF1).

Só de a gente estar realizando o curso, pra mim, é uma realização muito boa, fiquei, estou muito feliz com o curso e acho [...] vou te falar [... ] aprendi a mexer com o computador, a gente aprendeu muita coisa [...] pra mim é tudo novidade [...] (QEE6). 
As falas acima nos ajudam na reflexão do letramento digital. A primeira aparece como conceito restrito à aprendizagem da técnica, que se faz necessária para um curso à distância, ainda que não devesse ficar restrita à operacionalização da máquina, mas seu uso pelo sujeito para construção de sentidos, como ilustra a segunda fala. Ao aprender a mexer com o computador, esse sujeito estabeleceu interação com outros atores (E, PF, OA e TP) do curso e com o conhecimento técnico, extrapolando a operacionalidade da máquina.

Neste sentido, a valoração positiva do letramento digital é uma possibilidade de superação do problema da falta de domínio das TIC, por meio da apropriação das ferramentas digitais para dinamizar o processo ensino-aprendizagem, promovendo interação, mediação e apropriação de conhecimentos.

A não presença física apontada como problema por alguns, aqui aparece com valoração positiva, gerada pela flexibilidade de tempo, como um importante dado de acesso ao curso à distância, tal como citado por um $\mathrm{E}$ e um PF.

A valoração positiva também aparece aliada à democratização do acesso ao ensino superior, como podemos ilustrar nas falas abaixo.

[...] ponto positivo pra mim é a flexibilidade de horário, assim de acesso, e de comodidade de poder estar em casa [...] (QETP13).

[...] mais importante pra mim é a disponibilidade de tempo. [...] eu to fazendo um curso, to tocando então eu tenho uma rotina, no dia-a-dia enorme, que eu saio de manhã e chego só a noite [...] então a disponibilidade de tempo pra mim é ótima, e [...] assim [...] você tem uma comodidade, um conforto de estar em casa, estudando ali [...] (QETP15).

Para compreendermos a flexibilidade do tempo como valoração positiva recorremos à pesquisa realizada por Cruvinel, Lazzarotti Filho e Silva (2012), a qual apresenta que os estudantes desse curso são predominantemente trabalhadores, adultos acima dos 35 anos. Em sua maioria têm famílias já constituídas e, provavelmente, não conseguiriam sair dos municípios para estudar em outras cidades.

Abordamos aqui as valorações que se constituem pares como exemplo a flexibilidade do tempo e horário que se alia com a democratização do acesso ao ensino superior.

[...] o curso a distância tem um significado [...] pra formação daqueles jovens, então ah, nesse aspecto eu acho um ponto positivo, porque ele possibilita acesso a universidade a um maior número de jovens que querem estudar e que de outra maneira seria impossível [..] (QEPF8).

[...] eu considero que a modalidade a distância oportuniza ao maior número de pessoas terem acesso aos conhecimentos e isso para mim é muito importante, quer dizer elevar o nível de conhecimento das pessoas acerca daquilo que a humanidade produziu em termos de riqueza simbólica e riqueza social, então esse é o ponto positivo, ampliar o universo de possibilidade de outras pessoas acessarem o conhecimento (QEOA3).

O letramento digital alia-se a melhoria da comunicação: 


\begin{abstract}
A única coisa que eu posso dizer é que nos fóruns tinha discussões muito legais, mudança de atitudes, mudança de visão em relação aos próprios textos que eles leram (QEPF3).

É a questão da escrita... Quer dizer, por mais dificuldade que o estudante tenha, ele é obrigado a escrever [...] ele só se comunica por escrito na internet, nas plataformas. Ao escrever necessariamente esse estudante passa por um processo de reflexão que aqui no presencial, ouvindo muitas vezes ele não fala na aula, ele passa toda a matéria, toda disciplina lá como um ouvinte da disciplina (QEPF2).
\end{abstract}

Percebemos que os dois depoimentos nos remetem às práticas letradas mediadas pelo computador inserindo o estudante na construção das interações com outros sujeitos, indo para

além da operacionalidade técnica da máquina. Outra questão importante nesta discussão da melhoria da comunicação é a clareza na expressão escrita que Feenberg (2010) denominou de dialogo escrito. Para este autor, o ambiente "on- -line" é essencialmente um mundo escrito.

Por fim elencamos o desenvolvimento da autonomia que é recorrente das valorações

discutidas acima. A autonomia no curso à distância, qualidade positiva que está articulada com outras valorações mencionadas, ora aparece como sinônimo do autodidatismo, ora como independência do estudante.

Neste sentido o desenvolvimento da autonomia é justificado pela organização do tempo para o estudo, ou seja, pela flexibilidade do horário, letramento digital que faz com que o uso social dos instrumentos contribua para o desenvolvimento da autonomia, na busca por referências e na construção da aprendizagem via melhoria da comunicação.

\title{
Conclusão
}

O Curso de Licenciatura em EF desenvolvido em nove municípios do interior do Estado de Goiás apresenta um projeto pedagógico de aproximação com o curso presencial.

A estrutura didático-pedagógica do curso à distância agrega novas funções pedagógicas como PA, PF, OA e TP. Foi possível identificar uma estrutura em fase de consolidação, com os Polos ainda em estruturação, com experiências didáticas- pedagógicas em nível inicial e em fase de experimentação.

Dentre os principais problemas, destacam-se a falta de estrutura dos Polos, o não domínio das TIC, a intensificação do trabalho docente e a não presença física. Como qualidades destacam-se o letramento digital, a flexibilidade do tempo e de horário, a democratização do acesso ao ensino superior, a melhoria da comunicação através da escrita e o desenvolvimento da autonomia.

Estes são alguns dos principais elementos identificados na análise dos dados e que evidenciam o quanto há para conhecer nessa temática da formação profissional em EF na modalidade à distância. Curso e modalidade de crescimento exponencial no país, cuja complexidade, porém, não pode prescindir de novas investigações.

\section{THE DINAMICS, THE MAIN PROBLEMS AND THE QUALITIES IN THE DEVELOPMENT OF A PHYSICAL EDUCATION CAREER IN THE DISTANCE MODALITY}

\begin{abstract}
Research seeked to comprehend how a Physical Education career in the distance modality has been developed. The methodology was the study of case throughout the analisis of the
\end{abstract}


Pedagogical Curriculum Project and from 16 interviews. The career in question showed a structure in consolidation level, with ditatical-pedagogical experiences in inicial level and in experimentation phasis. It highlights as problems the Poles' lack of structure, the non-domain of Information and Comunication Tecnology, the intensification of docent labour and as the main qualities the autonomy, the digital literacy, the flexibility of schedule, the democratization of access to higher education and the improvements in comunicaton.

Key-words: Teachers formation; Distance learning; Physical Education.

\section{DINÁMICA, LOS PRINCIPALES PROBLEMAS y LAS CUALIDADES EN EL DESARROLLO DE UN CURSO GRADO EN EDUCACIÓN FÍSICA EN EL MODO DE DISTANCIA}

\section{Resumen}

Esta investigación busca entender cómo se está desarrollando una Licenciatura en Educación Física en la distancia. La metodología utilizada fue el estudio de caso a través del análisis de PPC y 16 entrevistas semi-estructuradas. El curso en cuestión presenta una estructura que se está consolidando con experiencias didácticas y pedagógicas en el nivel inicial y de juicio. Se destacan como problemas la falta de estructura del Polo, los no las tecnologías y la información y la comunicación - TIC y la intensificación de la labor docente. Las principales cualidades de autonomía extraído, alfabetización digital, la flexibilidad de las horas, la democratización del acceso a la educación superior y una mejor comunicación.

Palabras clave: Formación del profesorado; La educación a distancia; Educación Física.

\section{Referências}

BELLONI, M. L. Educação à distância. 3. ed. Campinas, SP: Autores Associados, 2003.

FIGUEIREDO, Z. C. C. Formação Docente em Educação Física: experiências sociais e relação com o saber. Revista Movimento, Porto Alegre: UFRGS, v. 10, n.1, p.89-112, jan./abri. 2004.

FEENBERG, A. A fábrica ou a cidade: qual é o modelo de educação a distância via web? IN: NEDER, R (Org.) A teoria critica de Andrew Feenberg: racionalização democrática poder e tecnologia. Brasília: Observatório do Movimento pela Tecnologia Social na América Latina/CDS / UnB / Capes, 2010.

GONZÁLEZ, F. J. O estudo do esporte na formação superior em Educação Física: construindo novos horizontes. Revista Movimento, Porto Alegre, v. 10, n. 1, p. 213-229, jan./abri. 2004.

LAZZAROTTI FILHO, A. O modus operandi do campo acadêmico-científico da educação física no Brasil. 2011. 147 p. Tese de doutorado apresentado ao Programa de PósGraduação em Educação Física da Universidade Federal de Santa Catarina. Florianópolis, SC, 2011.

NASCIMENTO, J. V. Metodologias de ensino dos esportes: avanços teóricos e implicações práticas. Revista Portuguesa de Ciências do Desporto, Porto, v. 4, n. 2, 2004. 
NIPPER, S. Third generation distance learning and computer conferencing. In R. Mason and A. Kaye (Eds.), Mindweave: Communication, computers and distance education. Permagon, Oxford, UK. 1989. p. 63-73.

NUNES, I. B. A História da EAD no mundo. In: Educação a distância: O estado da arte. LITTO, F. M.; FORMIGA, M (org.). São Paulo: Pearson Education, 2008.

RIVOLTELLA, P. C. Depois da educação a distância: tecnologia, educação e formação na Itália (1995-2008) In. Educação e Sociedade. Campinas, vol. 29, n. 104 - Especial, p. 851864, out., 2008.

CRUVINEL, F.; LAZZAROTTI FILHO, A.; SILVA, A. M. Análise comparativa do perfil dos estudantes dos cursos de licenciatura presencial e a distância em Educação Física da Universidade Federal de Goiás. In: Pensar a Pratica. V. 15, n.2, 2012.

PEREIRA, G. I. Letramento Digital e professores de LE: Formação para o uso das novas tecnologias em salas de aula. Dissertação apresentada no Programa de Pós-graduação em Lingüística - Universidade Federal de São Carlos, 2009.

PIRES, G. L.; NEVES, A. O trato com o conhecimento do esporte na formação em educação física: possibilidades para sua transformação didática. In: KUNZ, E. (Org.) Didática da Educação Física 2. Ijuí: UNIJUI, 2002. p. 53-95.

REZER, R. Reflexões didático-pedagógicas acerca do ensino do esporte no processo de formação de professores de Educação Física. Revista Movimento, v. 16, n. 1, p. 271-292, janeiro-março, 2010.

SILVA, A. M. ; NICOLINO, A. S. ; INACIO, H. L. D. ; FIGUEIREDO, V. C. . A Formação Profissional em Educação Física e o Processo Político-Social. Pensar a Prática (Online), v. 12, p. 01-15, 2009.

TARDIF, M. Saberes Docentes e formação profissional. Petrópolis, RJ: Vozes, 2002.

TAYLOR, J. Distance Education: The fifth Generation. $19^{\text {th }}$ ICDE Word Conference on Open Learning and distance Education, Viena, June 20-24, 1999.

Recebido em: 14/03/2015

Revisado em: 13/07/2015

Aprovado em: 01/09/2015

Endereço para correspondência:

Fernanda Cruvinel

fernandafefufg@gmail.com

Instituto Federal de Goiás,

Câmpus Goiânia

Rua 75, nº46. Centro. CEP: 74055-110. Goiânia/GO. 